\title{
EDUCAÇÃO DOS SURDOS NO PARÁ: AS TESES E DISSERTAÇÕES DE DOIS PROGRAMAS DE PÓS-GRADUAÇÃO
}

\author{
EDUCATION OF THE DEAF IN PARÁ: THESIS AND DISSERTATIONS OF TWO \\ POSTGRADUATION PROGRAMS
}

\author{
luanna Gabrielle Nascimento Mendes de Oliveira ${ }^{\mathrm{I}}$ \\ Joaquina Ianca Miranda ${ }^{2}$
}

RESUMO: O trabalho apresenta dados de um mapeamento das teses e dissertações que tem como tema central a Educação dos Surdos e que foram defendidas em dois programas de pós-graduação em Educação, um ofertado pela Universidade Federal do Pará e outro pela Universidade do Estado do Pará. O objetivo é identificar qual a frequência deste tema na produção desses programas e, assim, verificar em quais segmentos alinham-se as discussões do tema em questão. Para tanto, fez-se uso da técnica mapeamento sistemático, e analisou-se as monografias defendidas nos programas de pósgraduação indicados no recorte temporal de 2016 a 2019. Simultaneamente, foi desenvolvida uma pesquisa bibliográfica para a extração da base teórica sobre as questões que envolvem o tema e compreensão do seu histórico. Os resultados apontam a necessidade do desenvolvimento de pesquisas na perspectiva da Educação dos Surdos, embora seja o tema de mais destaque nos estudos de aprofundamento do âmbito da Educação Especial. Compreendemos que este estudo possibilita a identificação de lacunas a serem preenchidas no campo e que os dados indicam a necessidade de se estimular a produção científica nessa área no propósito de ampliar as possibilidades de possíveis soluções de problemas emergentes relacionados a essa demanda.

Palavras-Chave: Educação Especial. Educação dos Surdos. Pós-Graduação.

ABSTRACT: The work presents data from a mapping of the theses and dissertations that have as main theme the Education of the Deaf and that were defended in two graduate programs in Education, one offered by the Federal University of Pará and the other by the State University of Pará. The objective is to identify the frequency of this theme in the production of these programs and, thus, to verify in which segments the discussions of the theme in question are aligned. To this end, the systematic mapping technique was used, and the monographs defended in the graduate programs indicated in the time frame from 2016 to 2019 were analyzed. At the same time, a

\footnotetext{
1 Acadêmica de Pedagogia na Universidade Federal do Pará - UFPA; Atuando como Bolsista do Grupo de Pesquisa de Educação, Linguagem \& Subjetividade Surda (GPELISS) na UFPA, no projeto intitulado "Mapeamento de Instituições para o aluno surdo no Município de Belém". Área Inclusiva, Educação e Subjetividade Surda. http://lattes.cnpq.br/5413241637815116. E-mail: mendesluanna28@gmail.com.

${ }^{2}$ Graduanda do curso de Licenciatura Plena em Pedagogia na Universidade Federal do Pará (UFPA). Atuo como voluntária no desenvolvimento de pesquisas em História da Educação no Laboratório de Pesquisas em Memória e História da Educação (LAPEM) no projeto intitulado História da Educação no Pará na Primeira República, e na área de educação e saúde no Projeto de Extensão saúde na comunidade (PRESC). Bolsita PIBIC/PRODOUTOR no Projeto "Docência com bebês: reflexões sobre a criação cotidiana do currículo nas creches públicas de Belém, por meio de relatos (auto)biográficos das professoras".
} 
bibliographic research was developed to extract the theoretical basis on the issues that involve the topic and understanding its history. The results point to the need for the development of research from the perspective of the Education of the Deaf, although it is the most prominent theme in studies to deepen the scope of Special Education. We understand that this study allows the identification of gaps to be filled in the field and that the data indicate the need to stimulate scientific production in this area in order to expand the possibilities of possible solutions to emerging problems related to this demand.

Keywords: Special education. Deaf Education. Postgraduate studies.

\section{INTRODUÇÃO}

Este estudo tem como escopo mapear a produção científica de dois programas de pósgraduação em Educação do Estado do Pará no âmbito dos seus cursos de mestrado e doutorado, com base nas dissertações e teses ali defendidas. Para tanto, apresentamos um balanço da produção acadêmica no campo da Educação dos Surdos no período de 2016 a 2019. O levantamento das teses e dissertações foi realizado junto aos sites dos programas de pós-graduação em Educação da Universidade Federal do Pará (PPGED/UFPA) e da Universidade Estadual do Pará (PPGED/UEPA). Em seguida, fizemos a leitura dos títulos, resumos e palavras-chave tendo em vista sua classificação no tema estudado. Considerando dois critérios: aqueles que, de forma explícita, se apresentam como um estudo acerca da educação dos surdos no recorte temporal da pesquisa; e, aqueles que recorrem a uma modalidade Educacional da Educação dos Surdos na análise do objeto.

Este levantamento foi ensejado por meio da técnica de Mapeamento Sistemático, um estudo de ordem secundária em que se identifica, analisa-se e interpreta-se a produção em um objeto central de observação ou fenômeno investigado, possibilitando-nos identificar e classificar a produção científica de determinado campo em recorte temporal e espacial definido a priori (FALBO, 2018). Culminando na construção de um Estado do Conhecimento acerca da Educação dos Surdos nas teses e dissertações da pós-graduação no Pará. De acordo com Morosini e Fernandes (2014, p. 155), o "estado de conhecimento é identificação, registro, categorização que levem à reflexão e síntese sobre a produção científica de uma determinada área, em um determinado espaço de tempo, congregando periódicos, teses, dissertações e livros sobre uma temática específica”.

Este trabalho se justifica uma vez que,

as pesquisas de aprofundamento desenvolvidas pelos programas de pós-graduação são essenciais, visto que, delas emergem investigações relacionadas a questões pedagógicas que apresentam um caráter formativo e, portanto, somatório, pois devido serem realizadas periodicamente, atualizam o debate nesta esfera de conhecimento, permitindo que a análise das teorias de aprendizagem e desenvolvimento nas mais diversas situações educacionais sejam discutidas e 
ampliadas (MIRANDA; CARNEIRO; SOUZA; MIRANDA; MEDEIROS, 202I, p. 414).

Assim, essas discussões são determinantes para a produção de conhecimentos na área da Educação dos Surdos e refletem na concretude deste processo educacional. Ademais, compreender o estado do conhecimento deste campo, a partir de diferentes enfoques e contextos, resultam em indicativos em torno do desenvolvimento da pesquisa sobre a educação de surdos no Pará nos últimos anos, indicando possíveis tendências, perspectivas e lacunas, oferecendo subsídios para possíveis investigações no campo e contribuindo para o aprimoramento do âmbito em questão.

Foi realizada uma pesquisa bibliográfica para extração do aporte teórico de autores que tratam o tema Educação dos Surdos, assim como das bibliografias que ensejaram trabalhos similares a este. Nosso estudo, embora ainda inicial, se insere no rol de pesquisas que apresentam em comum a tarefa do mapeamento e da problematização de produçães acadêmicas no campo da Educação de Surdos, tendo em vista contribuir para transformações na realidade educacional de alunos surdos, ainda tão necessárias, por meio da compreensão deste campo de pesquisa, dentre eles destacamos: Ramos (2013), que indicou aumento gradativo das produções no campo, predomínio de dissertações, concentração de estudos nas regiões Sudeste e Sul, e a necessidade de avançar e estimular estudos que contemplem o âmbito; Pagnez e Sofiato (2014), que evidenciou o predomínio de dissertações de Mestrado, crescimento da produção de pesquisas e maior concentração de produção científica da área nas regiões Sudeste e sul, assim como o estudo anterior; e, a pesquisa de Ramos e Hayashi (2019) que corroboram com as demais e apontam as regiões Sudeste e sul do país como as que reúnem o maior número de dissertações e teses no universo analisado, e sinaliza o crescimento e avanço da área pesquisada.

Além desta introdução, em que apresentamos nossos objetivos para com este estudo, a metodologia adotada em sua realização, assim como suas justificativas, fazemos uma apresentação resumida dos estudos no campo da Educação dos Surdos, seguindo para a síntese do conjunto das produções que abordam o assunto nos programas analisados.

\section{Educação de Surdos: O saber através de teóricos na Área da Inclusão}

A educação de surdos ocorreu perante um processo de lutas por adaptações no processo de ensino, aprendizagem até a aceitação da Língua de Sinais como primeira modalidade a ser ensinada ao aluno, com a intenção de ser mediadora no processo de comunicação com o outro, debates e embates pelo público surdo. Nunes, Saia, Silva \& Mimessi (2015, p. 538) definem a surdez:

A surdez é uma alteração no sistema auditivo e/ou nas vias auditivas que reduz ou impede o acesso aos estímulos sonoros. Tal alteração dependerá da localização da 
perda (ouvido médio, interno, unilateral, bilateral, etc.); do momento da perda (antes ou depois da aquisição da linguagem, o que recebe nome de surdez pré ou pós linguística); e da intensidade da perda (leve, moderada, severa ou profunda) (NUNES \& org., 2015, p. 538).

Para compreender a especificidade e demandas desse público, é de suma importância explorar as modalidades adotadas na proposta educacional para com o público surdo. Primeiramente, a proposta oralista, que caminhava por uma perspectiva de proibição da comunicação através dos gestos, propondo que a comunicação fosse efetivada sem o uso da sinalização (SKLIAR, 1999). O método que consistia na concretização do verbalismo surgiu através do Congresso de Milão, ocorrido em I88o, que determinava o "método oral puro", demonstrando como melhor alternativa de ensino a ser repassada aos alunos surdos, pois iriam estimular o uso fonoaudiólogo de cada indivíduo, extinguindo assim, a Língua de Sinais da comunidade surda.

A proposta do bimodalismo forneceu ao aluno surdo a aprendizagem da modalidade oral da língua oficial de seu país, usando como instrumento de facilitação a linguagem gestual (sinais) juntamente com a perspectiva linguística escrita. Auxilia na utilização da sinalização uniformemente, e mesmo assim, distanciava o surdo da sua cultura, tornando-o um ser que desconhece sua própria particularidade. Dessa forma, percebe-se que o português permanece sendo o objetivo inatingível da instituição escolar, com a intenção de priorizar apenas uma possibilidade como correta no currículo escolar (FERNANDES, S. F. p. 6).

A perspectiva bilíngue é a mais aceita e utilizada nas metodologias escolares com alunos surdos, por buscar valorizar às duas modalidades (tanto a sinalização quanto a escrita), contribuindo para a apropriação do aluno por cada uma, destacando a Língua de Sinais como a primeira modalidade a ser ensinada ao indivíduo (LI), respeitando a particularidade da comunidade surda e fornecendo ao aluno a construção da escrita ( $\left.\mathrm{L}_{2}\right)$ com o auxílio da Língua de Sinais. Nunes e org. (2015, p. 542) afirmam que "[...] o bilinguismo pode ser um caminho de integração do surdo à escola e à sociedade por valorizar e facilitar a comunicação do indivíduo", pois irá fornecer à comunidade escolar a possibilidade de aquisição de uma nova língua. Para que isso se torne realidade, precisa-se de métodos e técnicas de ensino-aprendizagem para que o aluno possa operacionalizar os conteúdos presentes na estrutura curricular (BRASIL, 1997, p. 36).

Resende \& Lacerda (2013, p. 413) afirmam que:

Nos anos seguintes do ensino fundamental (a partir dos $6^{\circ}$ ano), ensino médio e ensino superior, o aluno surdo passa a frequentar salas de aula comuns do ensino regular, com o apoio do professor e tradutor de intérprete de Libras/Língua Portuguesa, que se coloca como mediador do conhecimento no âmbito escolar. Destaca-se que esse momento de escolarização deve continuar acontecendo a partir de uma perspectiva bilíngue. Nesse sentido, o professor regente deve conhecer e estar sensível às singularidades linguísticas desse aluno e o mesmo deve ser assistido, 
além do tradutor e intérprete de Libras/Língua Portuguesa, por um professor bilíngue para o ensino de Língua Portuguesa como segunda língua para pessoas surdas (REZENDE \& LACERDA, 2013, p. 413).

Ainda se percebe que as instituições se esforçam pouco para receber o aluno surdo, para planejar estratégias de ensino interligadas a sua língua materna, a presença de intérpretes para acompanharem o aluno com o uso de Libras na sala de aula, assim como o Atendimento Educacional Especializado no contraturno, a falta de formação continuada dos docentes, entre outros. Seguindo essa vertente, percebemos que a escola adequada para o aluno surdo deva seguir um currículo adaptado na língua materna do aluno (Língua de Sinais), intercalando o aprendizado da escrita com a utilização dos sinais, para dar funcionalidade ao aprendizado, demonstrando que através da escrita, o mesmo saberá se expressar através da leitura, etc. Além disso, que venha se fazer presente como disciplina obrigatória no currículo integral das turmas presentes na escola, promovendo um conhecimento e desenvolvimento através do saber, instigando e estimulando ouvintes a se comunicarem com os colegas surdos. Da mesma forma, a disciplina de Libras é obrigatória na grade curricular dos cursos de magistério, licenciatura e fonoaudiologia, de acordo com o decreto 5.526, de 2005, porém o mais eficaz seria toda e qualquer graduação fornecer o contato com a língua de sinais, para compreender e se apropriar da forma mais eficaz de ter uma mediação positiva com o surdo, além de auxiliar significativamente no aprendizado do mesmo.

Por certo, também é importante que o corpo ativo presente na instituição (porteiro, serventes, coordenadores, zeladores, professores, etc.) se aproprie da língua de sinais, fazendo assim que a inclusão seja parte do cotidiano do aluno na vida escolar, buscando, dessa forma, a possibilidade de ser incluso na particularidade do indivíduo surdo. Da mesma forma, Quadros (2005, p. 19) expressa em seus estudos que "[...] a educação bilíngue depende da presença de professores bilíngues. Assim, pensar em ensinar uma segunda língua pressupõe a existência de uma primeira língua. $O$ professor que assumir esta tarefa estará imbuído da necessidade de aprender a língua brasileira de sinais".

Por fim, é necessário estudar a subjetividade do sujeito surdo para fortalecer ainda mais a luta inclusiva desse público, principalmente por: respeitar a Língua de Sinais como a primeira língua $(\mathrm{LI})$, respeitando a particularidade; utilizar a sinalização como parte da mediação da comunicação e conhecimento nono espaço escolar; o uso da metodologia bilíngue como a principal utilizada como prática inclusiva na sala de aula; compreender a escrita como linguagem necessária a ser compreendida, e não apenas como decodificação; normas da língua internalizada do país por meio das interações em língua de sinais, contribuindo assim para o desenvolvimento do surdo; escrita como segunda modalidade ( 2 2) a ser repassada ao aluno, contribuindo para avanços na leitura, níveis 
abstratos, instigando a curiosidade e apropriação no aluno; adaptação no currículo presente na escola, promovendo uma inclusão efetiva para a melhor compreensão do aluno para com as disciplinas que serão executadas ao longo do semestre (SOUZA, 2019). Desta forma, compreendemos que o mapeamento realizado e cujoscujos resultados são apresentados a seguir

\section{Educação dos surdos nas teses e dissertações paraenses de dois Programas de pós-Graduação.}

Para compreender a produção nos Programas de Pós-Graduação em Educação selecionados, apresentaremos um pouco sobre esses programas destacando, brevemente, seu histórico e suas linhas de pesquisa. O Programa de Pós-Graduação em Educação da Universidade Federal do Pará (PPGED/UFPA) teve sua primeira proposta de mestrado homologada em $2003 \mathrm{e}$, em 2007, iniciouse o doutorado, cujo funcionamento vincula-se ao Instituto de Ciências da Educação (ICED) da UFPA e abrange três linhas de pesquisa: Políticas Públicas Educacionais; Currículo, Epistemologia e História; e Educação, Cultura e Sociedade (COELHO; SILVA, 2016). O Programa de PósGraduação em Educação da Universidade Estadual do Pará (PPGED/UEPA) situa-se no Centro de Ciências Sociais e Educação, e sua criação, e aprovação se deu em 2003, com credenciamento e reconhecimento em 2005, tendo como principais linhas de pesquisa a Formação de Professores e Saberes culturais e Educação na Amazônia (COELHO; SILVA, 2015). O doutorado deste programa ofertou a sua primeira turma no ano de 2019, com to vagas, no processo seletivo realizado em 2018 e, por esse motivo, não há produções bibliográficas defendidas no período delimitado.

A partir do mapeamento realizado nesses programas, foram identificadas as teses e dissertações que tinham seus temas centrados na Educação dos Surdos. Os resultados foram sumarizados em quadros e gráficos para evidenciar o cenário desse tipo de produção. Inicia-se pelo quantitativo total da amostra analisada e a quantidade de trabalhos na área delimitada, que se encontram expostos no quadro I e seu percentual de representação exposto no Quadro 2.

QUADRO I - Dissertações e Teses defendidas nos Programas de Pós-graduação e as Monografias que abordam a Educação dos Surdos, no período de 2016 a 2019.

\begin{tabular}{|c|c|c|c|}
\hline Instituição/programa & Dissertações & Teses & $\begin{array}{c}\text { Educação dos } \\
\text { Surdos }\end{array}$ \\
\hline PPGED/UFPA & I2I & 78 & I \\
\hline PPGED/UEPA & I62 & - & 4 \\
\hline
\end{tabular}

Fonte: Elaboração dos autores. 
QUADRO 2 - Percentual de trabalhos com ênfase em Educação dos Surdos (2016-2019)

\begin{tabular}{|c|c|c|}
\hline Natureza & PPGED/UEPA & PPGED/UFPA \\
\hline Dissertações & $2,46 \%$ & $0,82 \%$ \\
\hline Teses & - & $0 \%$ \\
\hline Índice Geral no PPG & $2,46 \%$ & $0,82 \%$ \\
\hline
\end{tabular}

Fonte: Elaborado pelos autores.

De acordo com os resultados coletados, pode-se observar a falta de material perante a educação de surdos, visto que são poucas as produções sobre a especificidade desse grupo. Libâneo (2004) afirma que a formação continuada é o prolongamento da formação inicial, com a intencionalidade de promover o aperfeiçoamento profissional, teórico e prático. $\mathrm{O}$ aprender é contínuo, e deve ser valorizado na vertente educacional, perante a educação especial e a inclusão do aluno surdo no ambiente escolar. $O$ ensino superior, por si só, não tem dado conta da demanda perante o conhecimento, saberes e "mitos" existentes dentro da Língua de Sinais: compreender a particularidade da língua estudada, questionar, responder dúvidas e indagar o aluno são práticas que devem ser levadas em consideração na disciplina, instigando e levando o discente a buscar leituras, cursos de libras, cursos de capacitação, pós- graduação, e até mesmo especialização na área inclusiva. Silva, Fernandes e Rocha (2016, p.63) afirmam que "construir coletivamente reflexão e conhecimentos sobre a política educacional para surdos e a necessidade de uma aplicação efetiva de educação de qualidade para esses sujeitos, desde a Educação Básica até a Universidade”, fazendo assim, a construção inclusiva através da equidade entre indivíduos ouvintes e surdos.

Além destes quantitativos, identificamos, no Quadro 3 e 4, as teses e dissertações mapeadas com seu autor, título, ano de defesa, tipo de monografia e área temática em cada um dos programas analisados. Para o agrupamento e categorização das monografias em respectivas áreas, utilizamos como estratégia metodológica a análise de conteúdo por meio do método indutivo, em que as categorias de análises emergem a partir do próprio material coletado, definindo-as a partir das temáticas abordadas nas monografias selecionadas. 
QUADRO $_{3}$ - Dissertações e Teses com tema, Educação dos Surdos, apresentadas no período de 2021 à 2019 no Programa de Pós-graduação em Educação da UFPA

\begin{tabular}{|c|c|c|c|c|}
\hline Autor & Título & Ano & Tipo & Área Temática \\
\hline $\begin{array}{c}\text { Ana Paula de } \\
\text { Araújo Barca }\end{array}$ & $\begin{array}{c}\text { Subjetivação e escolarização de um aluno } \\
\text { surdo usuário de implante coclear: um } \\
\text { estudo de caso fundamentado na } \\
\text { perspectiva histórico-cultural }\end{array}$ & 2017 & DISS & Inclusão escolar e \\
social
\end{tabular}

Fonte: Elaborado pelos autores com base nas informações do Repositório Institucional da Universidade Federal do Pará (2020).

QUADRO 4 - Dissertações e Teses com tema, Educação dos Surdos, apresentadas no período de 2021 à 2019 no Programa de Pós-graduação em Educação da UEPA

\begin{tabular}{|c|c|c|c|c|}
\hline Autor & Título & Ano & Tipo & Área Temática \\
\hline $\begin{array}{c}\text { Carina da Silva } \\
\text { Mota }\end{array}$ & $\begin{array}{c}\text { Glossário visual bilíngue na educação } \\
\text { de surdos: estudo sociolinguístico na } \\
\text { língua brasileira de sinais volume I }\end{array}$ & 2016 & DISS & $\begin{array}{c}\text { Linguagem/ } \\
\text { Bilinguismo }\end{array}$ \\
\hline $\begin{array}{c}\text { Pamela do } \\
\text { Socorro Da Silva } \\
\text { Matos }\end{array}$ & $\begin{array}{c}\text { Gestos de surdos e ouvintes: o contar } \\
\text { história sem uso da voz }\end{array}$ & 2016 & DISS & Linguagem \\
\hline $\begin{array}{c}\text { Carla da Silva } \\
\text { Mota }\end{array}$ & $\begin{array}{c}\text { Surdos bilíngues bimodais- um estudo } \\
\text { de caso sobre as interações } \\
\text { comunicacionais entre surdos falantes } \\
\text { nativos e falantes tardios }\end{array}$ & 2019 & DISS & $\begin{array}{c}\text { Inclusão escolar e } \\
\text { social }\end{array}$ \\
\hline $\begin{array}{c}\text { Vera Lúcia de } \\
\text { Cristo Lobato } \\
\text { adolescente surdo quilombola } \\
\text { Afirmações étnicas, conflitos culturais, } \\
\text { paradigmas educativos e estratégias } \\
\text { dialógicas }\end{array}$ & 2019 & DISS & $\begin{array}{c}\text { Inclusão escolar e } \\
\text { social/ Inclusão e a } \\
\text { temática } \\
\text { Etnicorracial }\end{array}$ \\
\hline
\end{tabular}

Fonte: Elaborado pelos autores com base nas informações do Programa de Pós-graduação em Educação da Universidade do Estado do Pará (2020)

Sobre as áreas temáticas identificadas nas nestes trabalhos elaborou-se o gráfico a seguir: 
GRÁFICO I - Áreas Temáticas abordadas nas Dissertações e Teses defendidas nos Programas de Pós-graduação estudados no período de 2016 a 2019.

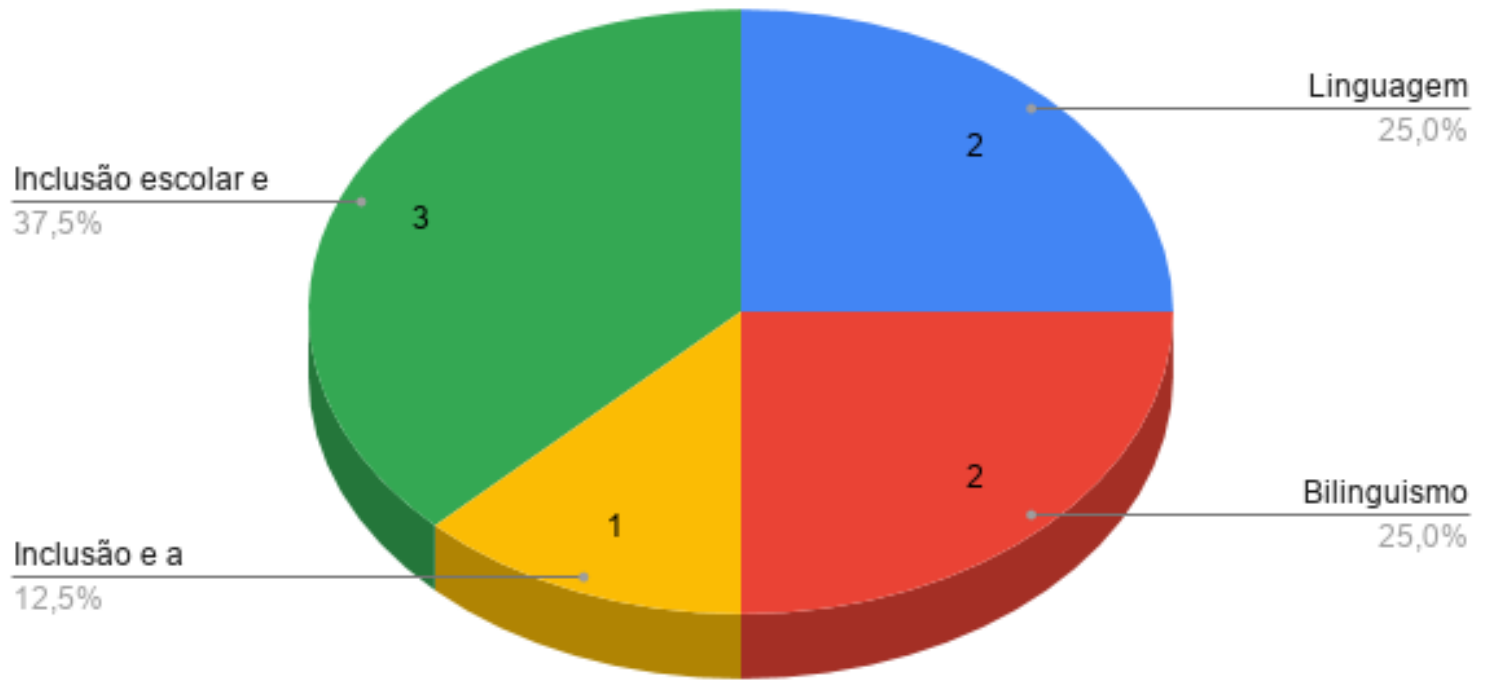

Fonte: Elaborado pelos autores com base nas informações do Programa de Pós-graduação em Educação da Universidade do Estado do Pará e do Repositório Institucional da Universidade Federal do Pará (2020)

No que cerne os temas abordados, nota-se que os estudos possuem quatro áreas privilegiadas, abordadas de forma associada umas às outras ou não, e que revelam as principais discussões na área: I) Inclusão escolar e social, que apresenta o maior percentual de representatividade, 37,5\%, abordado isoladamente em uma dissertação e associadamente em outras duas monografias; 2) Linguagem, que representa $25 \%$ das dissertações e teses analisadas, abordado em dois trabalhos de forma associada e isolada; 3) Bilinguismo, com percentual de $25 \%$ de representatividade e trabalhado apenas associadamente a outra temática; 4) Inclusão e a temática Etnicorracial, que é evidenciado em uma dissertação (12,5\%) associado a temática de inclusão. Corroboramos com Ramos e Hayashi (2019, p. 128) ao afirmarem que,

Os estudos que investigaram a produção científica sobre a surdez e sobre a educação de surdos nas últimas décadas revelaram, ainda, lacunas nesse campo de investigação, como a carência de pesquisas voltadas: à validação de testes para avaliação psicológica de crianças e de adolescentes surdos, aos processos psicopatológicos, ao atendimento à saúde física e mental da população surda, às relações familiares e ao implante coclear [...] 
Evidenciamos assuntos em torno da formação docente e da prática pedagógica presentes nos resumos, porém, se mostravam de forma secundária e ligados, principalmente, às temáticas sobre linguagem, bilinguismo e inclusão escolar. Inferimos que alguns temas, como a temática etnicoracial, assim como a abordagem no tema bilinguismo no que versa o processo de aquisição da língua de sinais, identificados nas dissertações aqui analisadas e identificadas, sinalizam alguns avanços no conhecimento que tem sido produzido no campo da Educação dos Surdos, no entanto, destacamos que o cenário atual dessa produção ainda se mostra incipiente e indicam a necessidade de estímulos a sua pesquisa.

\section{Considerações Finais}

Compreendemos que este estudo possibilita a identificação de lacunas a serem preenchidas no campo e que os dados indicam a necessidade de se estimular a produção científica nessa área, visto o baixo quantitativo dessa produção, com o propósito de ampliar as possibilidades de possíveis soluções de problemas emergentes relacionados a essa demanda. Embora seja possível reconhecer limitações da pesquisa ensejada, percebe-se que os resultados indicados podem vir a contribuir com o desenvolvimento da discussão acerca do objeto analisado nas produções monográficas dos respectivos Programas de Pós-Graduação.

Da mesma forma, observamos que as temáticas trabalharam mais a perspectiva da linguagem, da aquisição da Língua de Sinais ( $\left.\mathrm{L}_{1}\right)$ e Língua Escrita ( $\mathrm{L}_{2}$ ) segundo a linha do bilinguismo. Pode-se perceber também a falta de participação no campo de instituições, o contato com o indivíduo surdo, a práxis do estudo. Indicamos a importância de projetos de pesquisa que valorizem essa temática da Educação Especial, uma vez que os estímulos para essa produção acadêmica são extremamente necessários para se desvelar dificuldades e soluções nas tratativas dos sujeitos que necessitam de especificidades educativas para seu desenvolvimento escolar e integral.

\section{Referências}

BRASIL. Ministério da Educação. Secretaria de Educação Especial. O tradutor e intérprete da língua brasileira de sinais e a língua portuguesa. Programa Nacional de Apoio à Educação de Surdos - Brasília: MEC; SEESP, 2oo4b.

BRASIL. Ministério da Educação. Secretaria de Educação Especial. Educação Especial: a educação dos surdos. 2 vol. Série Atualidades Pedagógicas 04, Brasília: MEC/SEESP, 1997.

BRASIL. Decreto n. ${ }^{\circ} 5.626$, de 22 de dezembro de 2005. Regulamenta a Lei n. ${ }^{\circ}$ Io.436, de 24 de abril de 2002 e o artigo I 8 o da Lei no 10.098 , de 19 de dezembro de 2000 . Disponível em: 〈http://portal.mec.gov.br/seeps/>. Acesso em: jan./202I 
COELHO, W N B; SILVA, C A F. A produção intelectual docente na pós-graduação em Educação no norte do Brasil: avanços e desafios. Educação Unisinos. 20(3):387-399, setembro/dezembro 2016.

FALBO, R. A. Mapeamento sistemático. Vitória: Universidade Federal do Espírito Santo, 2018. Disponível em: http://www.inf.ufes.br/ falbo/files/MP/TP/Sobre_MS.pdf. Acesso em: 25 de março de 2020 .

FERNANDES, S. F. Práticas de letramento na educação bilíngüe para surdos. - Curitiba : SEED, 2006.

LODI, A. C. B., \& LUCIANO, R. R. (2010). Desenvolvimento da linguagem de crianças surdas em língua brasileira de sinais. (2. Ed.). In. A. C. B. Lodi \& C. B. F. de Lacerda (Eds), Uma escola, duas línguas: Letramento em língua portuguesa e língua de sinais nas etapas iniciais de escolarização) (pp. 23-47). Porto Alegre: Mediação.

MOROSINI, M C; FERNANDES, C M B. Estado do Conhecimento: conceitos, finalidades e interlocuções. Educação por escrito, Porto Alegre, v. 5, n. 2, p. 154-164, jul.dez. 2014 .

MIRANDA , J. I. S.; CARNEIRO, A. S.; SOUZA , B. M.; MIRANDA, K. M. B.; MEDEIROS, L. T. C. Pós-graduação e pesquisa: a educação especial como tema das dissertações e teses em dois programas de universidades públicas do Pará. Revista IberoAmericana de Humanidades, Ciências e Educação, [S. 1.], v. 6, n. I2, p. I4, 2021.

NUNES, S. da S.; SAIA, A. L.; SILVA, L. J.; MIMMESI, S. D’. A.; Surdez e educação: escolas e/ou bilíngues? Revista Quadrimestral da Associação Brasileira de Psicologia Escolar e Educacional, SP. Volume 19, Número 3, Setembro/Dezembro de 2015: 537-545

PAGNEZ, K. S.; SOFIATO, C. G. (2014). O estado da arte de pesquisas sobre a educação de surdos no Brasil de 2007 a 20II. Educar em Revista, 52, 229-256.

PPGED UEPA, Programa de Pós Graduação em Educação da Universidade do Estado do Pará - UEPA/CCS, Dissertações de Mestrado Defendido, 2020. Disponível em: http://ccse.uepa.br/ppged/?page_id=650. Acesso em: 28 de março de 2020.

QUADROS, R. M. O "bi” do bilingüismo na educação de surdos. In: Surdez e bilingüismo. Porto Alegre: Editora Mediação, 2005.

RAMOS, D. M. Análise da produção acadêmica constante no Banco de Teses da Capes segundo o assunto educação de surdos (2005-2009). Dissertação de Mestrado. Universidade Estadual Paulista, Araraquara, SP, Brasil. 2013

RAMOS, D M; HAYASHI, M C P I. Balanço das Dissertações e Teses sobre o Tema Educação de Surdos (2010-2014). Rev. bras. educ. espec, p. II7-132, 2019. 
REPOSITÓRIO DA UFPA, Repositório Institucional da Universidade Federal do Pará, Biblioteca Central UFPA/SIBI, 2020. disponível em: http://repositorio.ufpa.br/jspui/. Acesso em: 28 de março de 2020 .

RESENDE, A. A. C. de.; LACERDA, C. B. F. de.; Mapeamento de Alunos Surdos Matriculados na Rede de Ensino Pública de um Município de Médio Porte do Estado de São Paulo: Dissonâncias. Rev. Bras. Ed. Esp., Marília, v. 19, n. 3, p. 4II-424, Jul.-Set., 2013

SKLIAR, C. (org). [Orelha do livro]. In: STRNADOVÁ, V. Como é ser surdo. Tradução de Daniela Richter Teixeira. Rio de Janeiro: Babel Editora, 2000.

Atualidade da educação bilíngüe para surdos. Porto Alegre: Mediação, I999.

SOUZA, C. T. R. A expressão do sujeito surdo por meio da escrita em língua portuguesa. Tese (doutorado), Universidade Federal de São Carlos, campus São Carlos. 2019. 